\title{
Etiological Analysis of Neurodevelopmental Disabilities: Single-Center Eight-Year Clinical Experience in South China
}

\author{
Li Guo, ${ }^{1}$ Bing-Xiao Li, ${ }^{1}$ Mei Deng, ${ }^{1}$ Fang Wen, ${ }^{1}$ Jian-Hui Jiang, ${ }^{2}$ \\ Yue-Qiu Tan, ${ }^{3}$ Yuan-Zong Song, ${ }^{1}$ Zhen-Huan Liu, ${ }^{4}$ Chun-Hua Zhang, \\ Keiko Kobayashi, ${ }^{6}$ and Zi-Neng Wang ${ }^{7}$ \\ ${ }^{1}$ Department of Pediatrics, The First Affiliated Hospital, Jinan University, No.613, Huangpu Dadao Xi, Guangzhou 510630, China \\ ${ }^{2}$ Guangzhou Neonatal Screening Center, Guangzhou Women and Children's Medical Center, Guangzhou 510180, China \\ ${ }^{3}$ Institute of Reproduction and Stem Cell Engineering, Xiangya School of Medicine, Central South University, Changsha 410078, China \\ ${ }^{4}$ Department of Pediatric Neurorehabilitation, Nanhai Maternity and Child Care Hospital, Guangzhou University of Chinese \\ Medicine, Foshan 528200, China \\ ${ }^{5}$ Department of Research and Development, Matsumoto Institute of Life Science International, Kanazawa 921-8154, Japan \\ ${ }^{6}$ Department of Molecular Metabolism and Biochemical Genetics, Kagoshima University Graduate School of Medical and \\ Dental Sciences, Kagoshima 890-8544, Japan \\ ${ }^{7}$ Department of Gynecology and Obstetrics, The First Affiliated Hospital, Jinan University, Guangzhou 510630, China
}

Correspondence should be addressed to Yuan-Zong Song, songyuanzong@tom.com

Received 13 May 2010; Accepted 30 July 2010

Academic Editor: Veikko Salomaa

Copyright () $2011 \mathrm{Li}$ Guo et al. This is an open access article distributed under the Creative Commons Attribution License, which permits unrestricted use, distribution, and reproduction in any medium, provided the original work is properly cited.

\begin{abstract}
Etiology determination of neurodevelopmental disabilities (NDDs) currently remains a worldwide common challenge on child health. We herein reported the etiology distribution feature in a cohort of 285 Chinese patients with NDDs. Although concrete NDD etiologies in $48.4 \%$ of the total patients could not be identified, genetic diseases (with the proportion of $35.8 \%$ in the total cases) including inborn errors of metabolism (IEM) and congenital dysmorphic diseases, constituted the commonest etiology category for NDDs in this study. The two key experimental technologies in pediatric metabolomics, gas chromatography-mass spectrometry (GC-MS), and tandem mass spectrometry (MS-MS), proved to be substantially helpful for the exploration of the NDD etiologies in this clinical investigation. The findings in this paper provided latest epidemiologic information on the etiology distribution of NDDs in Chinese, and the syndromic NDDs caused by citrin deficiency and the novel chromosomal karyotype, respectively, further expanded the etiology spectrum of NDDs.
\end{abstract}

\section{Introduction}

With global developmental delay (GDD) and mental retardation (MR) as two main clinical subtypes, neurodevelopmental disabilities (NDDs), which are defined as a group of chronic clinically distinct disorders that all share a documented disturbance, quantitative, qualitative, or both, in developmental progress in one or more developmental domains compared with established norms [1], are conventionally categorized into syndromic type which is characterized by associated clinical, radiological, metabolic or biological features, and nonsyndromic type in which NDD represents the only manifestation. The precise prevalence of NDDs remains unclear, but this entity has been estimated to affect $5 \%$ to $10 \%$ of children [2]. In developed countries, MR has become the most frequent cause of severe handicap in children and one of the main reasons for referral in clinical genetic practice [3]. Actually, $1 \%$ to $3 \%$ of children younger than 5 years have been reasonably given the prevalence of MR in a specific population [4]. As the largest developing country in the world with a population over 1.3 billion, China also faces the difficult challenge of NDDs on its child health. An investigation in the year 2000 has revealed that the MR incidence in children below 6 years of age was $0.931 \%$, 
and 136,000 children with MR were increased annually in mainland of our country [5]. Etiology determination of NDDs was essential not only for the option of therapeutic imperatives and evaluation of clinical outcomes and recurrence risks but also for other benefits including avoidance of unnecessary tests and access to appropriate patients for accumulating management experiences, however, this issue also remains far from resolved at the current stage in pediatric practice. In this paper, we reported our eight-year findings on NDD etiologies in a medical center in south China.

\section{Subjects and Methods}

2.1. Patients. The research subjects recruited in this study were all patients referred to, from April 2002 to March 2010, Department of Pediatrics, First Affiliated Hospital, Jinan University, Guangdong, China. The GDD/MR diagnosis in most cases was made by at least 2 pediatric physicians in different hospitals in accordance with the updated concepts in the review [1]. For some cases who suffered from other clinical problems such as liver diseases and malformations, NDD was noticed and then confirmed in our department. The patients in this study came from 22 provinces, municipalities, and autonomous regions in China, respectively, with most of them from Guangdong Province.

2.2. Clinical Data. History inquiry and physical examination were performed on all the NDDs patients in our pediatric clinic or award and the positive findings were recorded and preserved by the authors. Most of the laboratory and imaging results were collected from the corresponding databases in our hospital, besides some provided by parents of the patients at their referral to the authors for clinical counseling. In this study we, by means of a cross-sectional study, retrospectively analyzed and summarised the clinical information collected in the past 8 years.

2.3. Gas Chromatography-Mass Spectrometry (GC-MS). Selective screening of inborn errors of metabolism (IEMs) in this study was conducted by analysis of the urinary components, using an urease pretreatment GC-MS procedure, mainly with a Finnigan GC-MS instrument (TRACE DSQ), with detailed information described previously by our group $[6]$.

2.4. Tandem Mass Spectrometry (MS-MS). Amino and acyl carnitine in dried blood stains was analyzed by means of a MS-MS procedure, and sample preparation, apparatus settings, and data analysis were based on the detailed information described in [7]. The analysis was conducted with an API 3200 tandem mass spectrometer purchased from Applied Biosystems. Neutral loss scan and precursor scan were used for the analysis of most amino acids and acyl carnitines, respectively, while multiple reaction monitoring (MRM) was utilized for the detection of glycine, ornithine, arginine, and citrulline as well.
TABle 1: Main clinical manifestations besides NDDs and the positive laboratory and imaging findings in syndromic NDDs.

\begin{tabular}{lcc}
\hline No. & Positive findings & Cases \\
\hline 01 & Failure to thrive & 81 \\
02 & Seizure/convulsion & 37 \\
03 & Hearing disability & 28 \\
04 & Dysmorphic facial features & 25 \\
05 & Abnormal urine odor & 20 \\
06 & Eye movement obstacles & 19 \\
07 & Vomitting & 18 \\
08 & Hair depigmentation & 15 \\
09 & Microcephaly & 11 \\
10 & Skin abnormalities & 10 \\
11 & Hepato/splenomegaly & 10 \\
12 & Impaired swallowing and chewing & 5 \\
13 & Fondus ocili abnormalities & 4 \\
14 & Vision problem & 4 \\
15 & Abnormal lens & 3 \\
16 & Genitalia malformation & 3 \\
17 & Metabolic acidosis & 46 \\
18 & Hyperammonemia & 12 \\
19 & Abnormal EEG & 22 \\
20 & Skeleton abnormality on X ray & 5 \\
21 & CT/MRI abnormal findings & 85 \\
\hline
\end{tabular}

2.5. Chromosome Karyotype Analysis. Traditional chromosomal banding was performed in NDD patients suspected to have chromosomal abberations. Fluorescence in situ hybridization (FISH) was further used, when necessary, to determine the complex karyotypes as previously described [8]. Briefly, the peripheral blood lymphocytes were cultured under phytohemagglutinin (PHA) stimulation and treated with colcemid and harvested by standard methods. Metaphases were spread on clean slides, and standard Gbanding with trypsin-Giemsa was performed. The slides for FISH were stored at $-20^{\circ} \mathrm{C}$ before use. The denatured FISH probe (Abbott-Vysis, Downers Grove, IL, USA) was added to the denatured slides with metaphase spreads in a moist chamber for hybridizing over night. After washing, the slide was counterstained with DAPI in an antifade solution. The hybridized metaphase chromosomes were captured and analyzed using a digital image analysis system containing an Olympus BX51 microscope equipped with LUCIA Cytogenetics system (Prague, Czech Repuplic).

2.6. SLC25A13 Gene Mutation Analysis. The diagnosis of citrin deficiency was confirmed by mutation analysis of the causative gene SLC25A13. Four hotspot mutations, 851854del(851del4), IVS6 + 5G > A, IVS16ins3kb, and 16381660dup were screened by means of the routine approaches described in reference [9]. In this study, the sequences of the forward and backward primers for PCR amplification of the mutation 851del4 were $5^{\prime}$-ggtatattgttgcttgtgtttg- $3^{\prime}$ and $5^{\prime}$ tcttccagaggagcaatccg- $3^{\prime}$, respectively. 


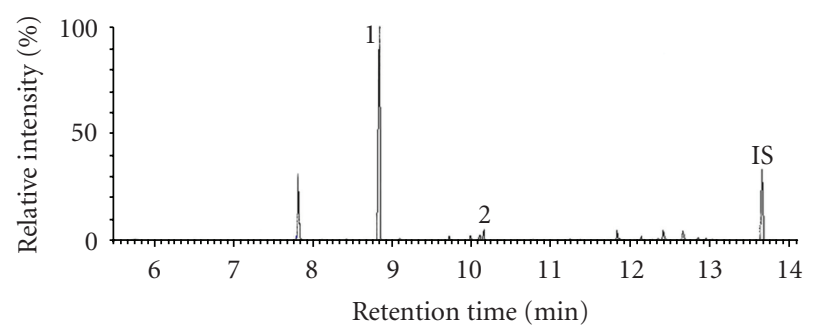

(a)

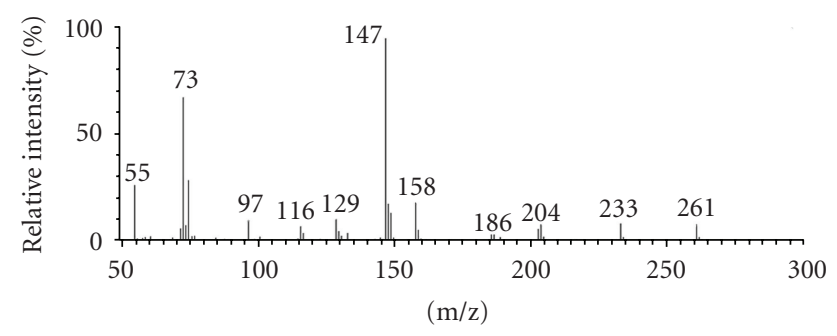

(b)

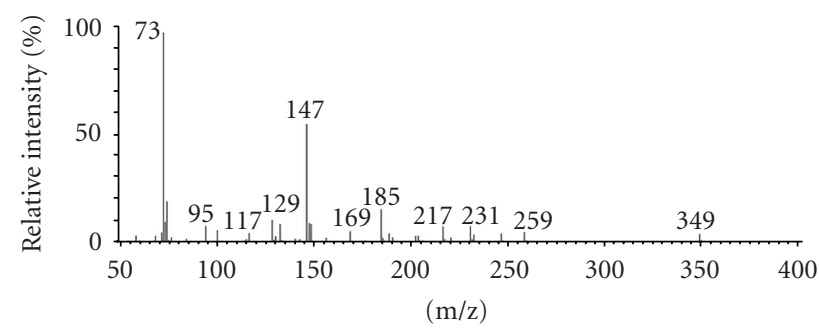

(c)

FIGURE 1: Chemical diagnosis of glutaric acidemia type I by GC-MS analysis of urinary metabolites for a 9-month-old female with motor and language retardation. Figure 1(a) is a representative GC-MS total ion current (TIC) profile, in which intensities of peak 1 and 2 were both dramatically increased. IS is the abbreviation of internal standard. Figures 1(b) and 1(c), the mass spectra for peak 1 and 2 in Figure 1(a), revealed their identifications as trimethylsilyl derivatives of glutarate and 3-hydroxyglutarate, respectively.

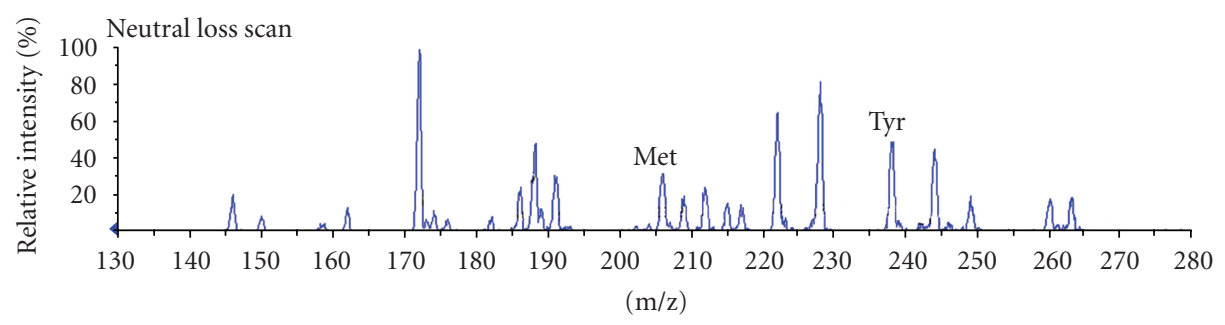

(a)

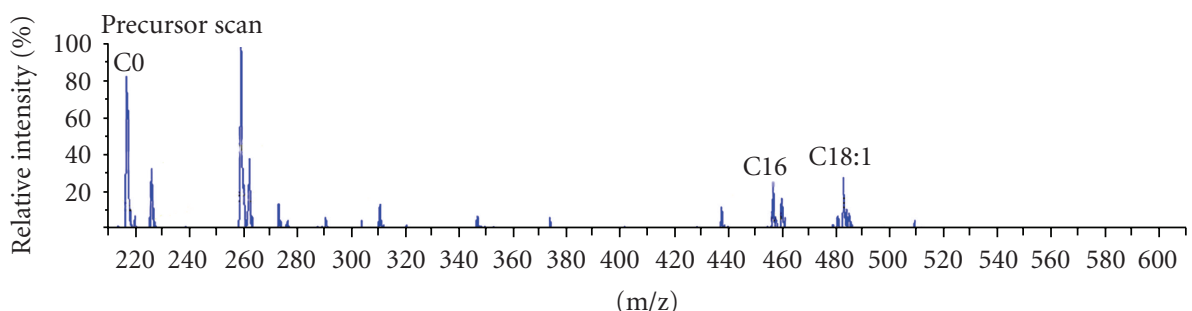

(b)

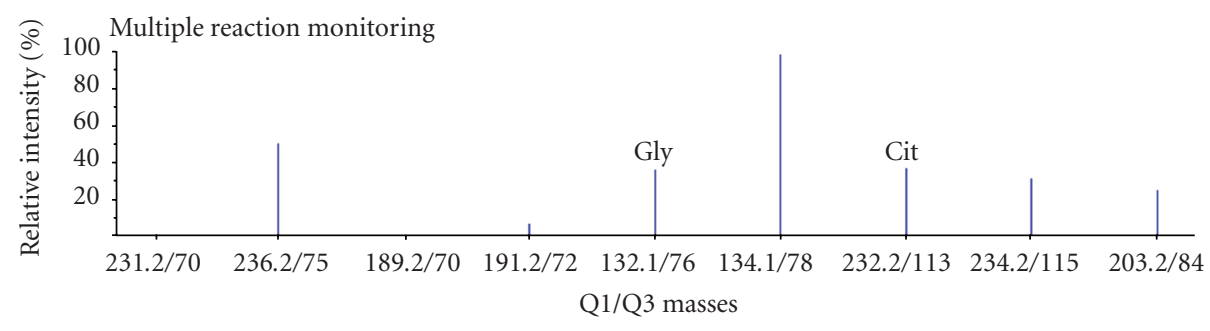

(c)

FIGURE 2: Chemical diagnosis of citrin deficiency by MS-MS analysis of amino and acyl carnitines in dried blood stain from a 16-monthold male toddler (C0013) with syndromic GDD. Figures 2(a), 2(b), and 2(c) are profiles of neutral loss scan, precursor scan, and multiple reaction monitoring, respectively. The amino and acyl carnitines with increased levels were labeled as abbreviations, with Met, Tyr, Gly, Cit, $\mathrm{C} 0, \mathrm{C} 16$, and C18: 1 representing methionine, tyrosine, glycine, citrulline, free carnitine, palmitate, and hydroxypalmitate, respectively. 
TABLE 2: Etiology distribution in the whole cohort of NDDs.

\begin{tabular}{lcccl}
\hline Etiology categories & Disease types & Case number & Proportion & Concrete disease (case number) \\
\hline Genetic diseases & 50 & 102 & $35.8 \%$ & Detailed information in Table 3 \\
Psychobehaviour & 3 & 23 & $8.1 \%$ & Autism (21, including 5 cases of Rett syndrome); ADHD (2) \\
Acquired brain injuries & 2 & 7 & $2.4 \%$ & Kernicterus (4); HIE (3) \\
Other etiology & 2 & 15 & $5.3 \%$ & Cerebral palsy (7), Epilepsy (8) \\
Unknown & 1 (NDDs) & 138 & $48.4 \%$ & No concrete etiologies were identified at the current stage \\
In total & 58 & 285 & $100 \%$ & - \\
\hline
\end{tabular}

TABLE 3: Etiology distribution in the patients with genetic diseases in Table 2.

\begin{tabular}{|c|c|c|c|c|}
\hline Etiology categories & Disease types & Case number & Proportion & $\begin{array}{l}\text { Concrete diseases (case } \\
\text { number) }\end{array}$ \\
\hline IEMs & 27 & 66 & $64.7 \%$ & $\begin{array}{l}\text { Detailed information in } \\
\text { Table } 4\end{array}$ \\
\hline Congenital dysmorphic diseases & 14 & 22 & $21.6 \%$ & $\begin{array}{l}\text { Detailed information in } \\
\text { Table } 5\end{array}$ \\
\hline Chromosomal abberations & 4 & 6 & $5.9 \%$ & $\begin{array}{l}\text { Detailed information in } \\
\text { Section } 3.5\end{array}$ \\
\hline Endocrine disorders & 3 & 4 & $3.9 \%$ & $\begin{array}{l}\text { Hypoparathyroidism (1), } \\
\text { Pseudohypoparathyroidism } \\
\text { (1), Congenital } \\
\text { hypothyroidism (2) }\end{array}$ \\
\hline Others & 2 & 4 & $3.9 \%$ & $\begin{array}{l}\text { Congenital muscular } \\
\text { dystrophy (3), Progressive } \\
\text { muscular dystrophy (1) }\end{array}$ \\
\hline In total & 50 & 102 & $100 \%$ & - \\
\hline
\end{tabular}

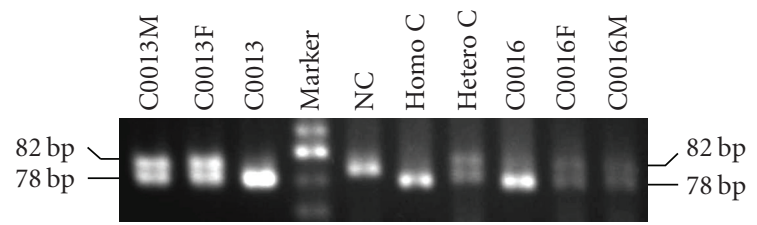

Figure 3: PCR-gel electrophoresis analysis of mutation 851del4 in the gene SLC25A13 of the two families with citrin-deficient patients C0013 and C0016. NC, Homo C and Hetero C in this figure are abbreviations of Normal Control, Homozygous Control and Heterozygous Control, respectively. F and $\mathrm{M}$ in the two families represent Father and Mother, respectively. The $78 \mathrm{bp}$ PCR products in both patients are $4 \mathrm{bp}$ shorter than the normal size $82 \mathrm{bp}$, suggesting that the 2 patients are both 851 del 4 homozygotes, and their parents all carriers of the same mutation.

2.7. Electronic Microscopy. The muscular ultrastructure changes were observed by transmission electronic microscopy in patients suspected to have Leigh syndrome and muscular dystrophy, with biopsy samples from musculi gastrocnemius. Muscular tissue was fixed in $2.5 \%$ glutaraldehyde and post-fixed in 1\% osmium tetroxide solution, and then embedded in epoxy resin before semithin sectioning, as described in reference [10]. Two electronic microscope instruments (JOEL-CX100 and Philips-Tecai-10) were utilized for ultrastructure observation in our investigation.

This study was performed with the informed consents from the parents of the patients, adhering to the principles of the Declaration of Helsinki. In particular, SLC25A13 mutation analysis has been approved by the Committee for Medical Ethics in the First Affiliated Hospital, Jinan University, while chromosome karyotype analysis by that in Reproductive and Genetic Hospital of Citic-Xiangya, Central South University.

\section{Results}

3.1. General Information and Semiology. The NDDs cohort in this study was composed of 285 cases in total, including 191 males and 94 females. The median age at referral was 1 year and 7 months, with minimum 1 week, and maximum 16 years. The whole cohort included 240 syndromic and 45 nonsyndromic NDD cases, with the relative proportion of $84.2 \%$ and $15.8 \%$, respectively. The main clinical manifestations besides NDD and the laboratory and imaging findings in the syndromic NDDs were summarized in Table 1 .

3.2. Etiology Distribution. As shown in Table 2, no concrete etiologies, unfortunately, were found for $48.4 \%$ of the total patients, but NDDs in the remaining $51.6 \%$ could be attributed to complex and diverse etiologies, among which genetic diseases were on top of the list of the identified causes. Further analysis in Table 3 revealed that IEMs took the first place in genetic etiologies, and then came congenital dysmorphic disorders. These 2 entities constituted 
TABLE 4: Feature of etiology distribution in the patients with IEMs in Table 3.

\begin{tabular}{|c|c|c|c|c|}
\hline Categories & Diseases* & Cases & Major diagnostic evidences & Clinical outcomes \\
\hline \multirow{2}{*}{$\begin{array}{l}\text { Disorders of } \\
\text { Carbohydrate } \\
\text { metabolism }\end{array}$} & Galactosemia & 1 & $\begin{array}{l}\text { Clinical features including congenital } \\
\text { cataract and leukodystrophy, and } \\
\text { GC-MS analysis }\end{array}$ & Lost contact \\
\hline & Fructosuria & 2 & GC-MS analysis & Both lost contact \\
\hline \multirow{7}{*}{$\begin{array}{l}\text { Disorders of } \\
\text { Amino acid } \\
\text { metabolism }\end{array}$} & Phenylketonuria & 7 & $\begin{array}{l}\text { GC-MS analysis in } 6 \text { cases, and PAH } \\
\text { gene analysis in } 1 \text { case }\end{array}$ & $\begin{array}{l}\text { Referred to local network of } \\
\text { management and } 2 \text { died after } \\
\text { treatment withdrawal }\end{array}$ \\
\hline & Histidinemia & 1 & Repeated MS-MS analysis & Lost contact \\
\hline & Hyperhomocysteinemia & 2 & $\begin{array}{l}\text { Total plasma homocysteine levels and } \\
\text { MS-MS analysis }\end{array}$ & $\begin{array}{l}1 \text { died, and } 1 \text { stable without obvious } \\
\text { clinical or biochemical improvement }\end{array}$ \\
\hline & Pyroglutamic acidemia & 1 & GC-MS analysis & Lost contact \\
\hline & Tyrosinemia type I & 1 & GC-MS and MS-MS findings & Died due to acute liver failure \\
\hline & Hyperglycinemia & 1 & GC-MS and MS-MS analysis & $\begin{array}{l}\text { Intractable seizures and behavioral } \\
\text { problem }\end{array}$ \\
\hline & Canavan's disease & 1 & GC-MS analysis & Lost contact \\
\hline \multirow{9}{*}{$\begin{array}{l}\text { Organic } \\
\text { acidemia }\end{array}$} & Methylmalonic acidemia & 11 & $\begin{array}{l}\text { GC-MS, MS-MS and MMACHC gene } \\
\text { analysis, with } 5 \text { combined with } \\
\text { hyperhomocysteinemia }\end{array}$ & $\begin{array}{l}5 \text { died after withdrawal of treatment, } 3 \\
\text { improved and } 3 \text { lost contact }\end{array}$ \\
\hline & Maple syrup urine disease & 2 & GC-MS and MS-MS analysis & Both died \\
\hline & Ethylmalonic acidemia & 1 & GC-MS analysis & Lost contact \\
\hline & Propionic acidemia & 3 & GC-MS analysis & $\begin{array}{l}2 \text { stable with episodic } \\
\text { hyperammonemia, and } 1 \text { lost contact }\end{array}$ \\
\hline & Glutaric acidemia type I & 2 & GC-MS and MS-MS analysis & 1 lost contact and 1 stable \\
\hline & Glutaric acidemia type II & 1 & GC-MS analysis & Stable \\
\hline & 2-hydroxyglutaric acidemia & 1 & GC-MS analysis & Lost contact \\
\hline & 4-hydroxybutyric aciduria & 1 & GC-MS and ALDH5A1 gene analysis & Stable but with seizure episodes \\
\hline & Multiple carboxylase deficiency & 4 & $\begin{array}{l}\text { GC-MS, biotinidase activity, and } \\
\text { HLCS gene analysis }\end{array}$ & 1 died, 3 recovered/improved clinically \\
\hline \multirow{3}{*}{$\begin{array}{l}\text { Urea cycle } \\
\text { disorders }\end{array}$} & OTCD & 2 & GC-MS and MS-MS analysis & Recovered clinically \\
\hline & Hyperammonemia & 4 & $\begin{array}{l}\text { Markedly increased serum ammonia } \\
\text { levels, but with etiologies } \\
\text { undetermined yet }\end{array}$ & All lost contact \\
\hline & Citrin deficiency & 2 & SLC25A13 mutation analysis & $\begin{array}{l}1 \text { died due to liver cirrhosis, } 1 \\
\text { improved }\end{array}$ \\
\hline $\begin{array}{l}\text { Mitochondrial } \\
\text { disease }\end{array}$ & Leigh syndrome & 5 & $\begin{array}{l}\text { Clinical and imaging features, } \\
\text { serum/CSF lactate levels, and } \\
\text { electronic microscopy findings on } \\
\text { muscle biopsy samples }\end{array}$ & $\begin{array}{l}3 \text { died already, and the remaining } 2 \\
\text { stable at follow-up }\end{array}$ \\
\hline \multirow{2}{*}{$\begin{array}{l}\text { Lysosome } \\
\text { storage } \\
\text { diseases }\end{array}$} & Mucopolysaccharidosis type I & 1 & Typical clinical manifestations & $\begin{array}{l}\text { Improved after bone marrow } \\
\text { transplantation }\end{array}$ \\
\hline & Mucopolysaccharidosis type II & 2 & $\begin{array}{l}\text { Activity analysis of } \\
\text { iduronate-2-sulphatase }\end{array}$ & Lost contact \\
\hline $\begin{array}{l}\text { Peroxisomal } \\
\text { disorders }\end{array}$ & X-linked adrenoleukodystrophy & 2 & $\begin{array}{l}\text { Clinical manifestations, CT/MRI } \\
\text { findings, and MS-MS analysis of } \\
\text { VLCFA }\end{array}$ & Both Died \\
\hline \multirow[t]{2}{*}{ Others } & Glyceroluria & 4 & GC-MS analysis & $\begin{array}{l}1 \text { died after severe infection, } 3 \text { lost } \\
\text { contact }\end{array}$ \\
\hline & 3-aminoisobutyric aciduria & 1 & GC-MS analysis & Lost contact \\
\hline
\end{tabular}

${ }^{*}$ Some diseases have been reported in [6] as GC-MS screening results, and this list herein is the latest update of our findings, just focusing on the IEMs associated with NDDs. 


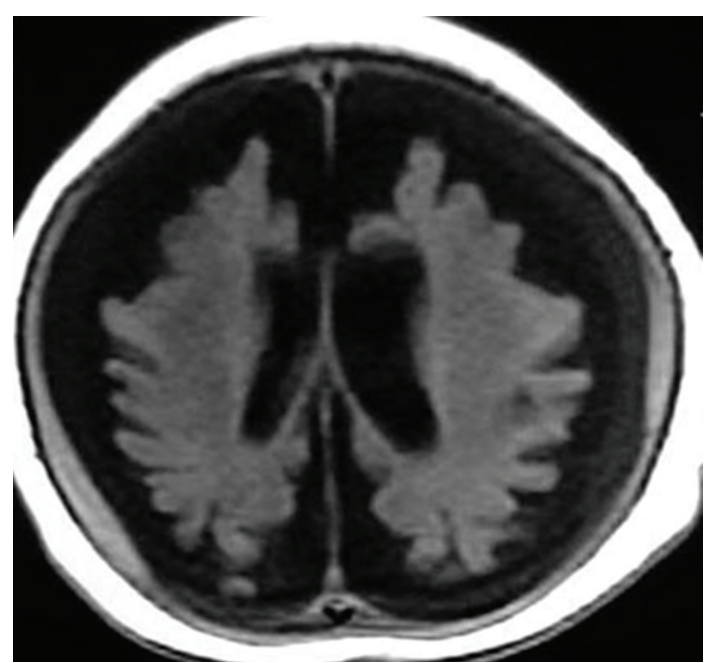

(a)

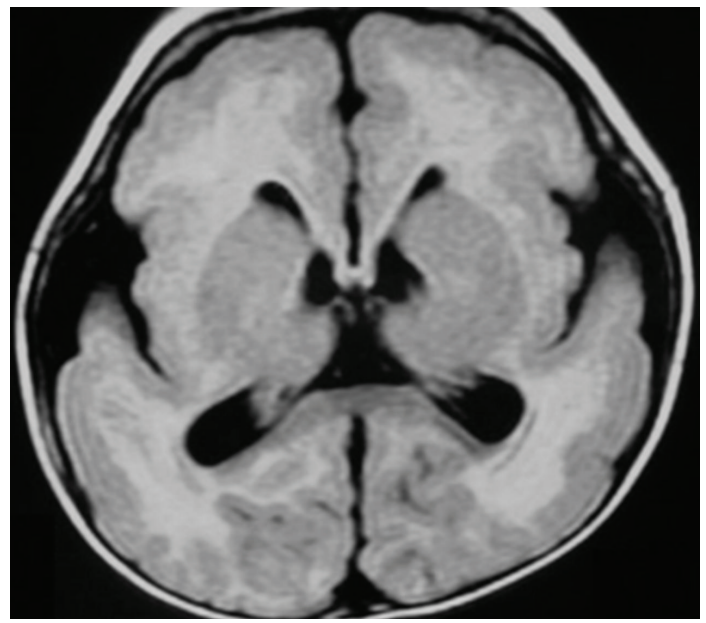

(c)

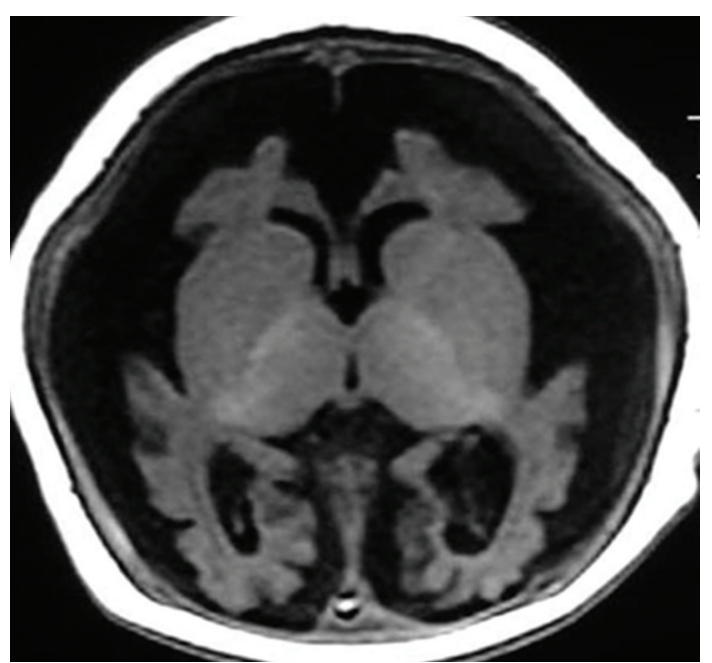

(b)

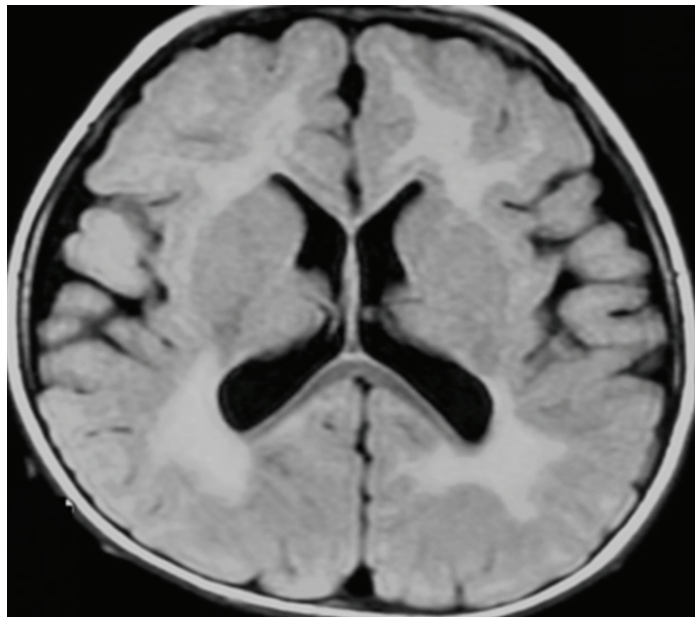

(d)

Figure 4: Representative MRI findings in different malformations of cortical development (MCD). Figures 4(a) and 4(b) showed severe cortex dysplasia in bilateral parietal lobes and frontal, temporal and occipital lobes, respectively, in the telencephalon of a 5-month-old male with NDD. Figure 4(c) demonstrated typical lissencephaly in a 9-month-old female with Miller-Dieker syndrome. The white matter volume was decreased while the cortex was thick and smooth due to lack of enough sulcation, forming the so-called pachygyria malformation, and the thickened and irregular cortex in Figure 4(d) revealed the cobblestone cortical malformation in a patient with muscle-eye-brain disease.

the overwhelming majority in the genetic diseases. Other causes such as chromosome and endocrine abnormalities were also identified, just accounting for a minority less than $14 \%$ in the total genetic etiologies.

3.3. IEMs. As listed in Table 4, 66 patients with IEMs of 27 types and 8 categories were diagnosed in this NDD cohort. The traditional clinical, biochemical, and imaging findings were indispensable during the diagnostic processes, however, the applications of two metabolome tools, GC-MS and MSMS, were substantially helpful in the exploration of the NDD etiologies in this study. Figure 1 demonstrated the diagnostic evidences of glutaric acidemia type I by GC-MS analysis of urine sample. In particular, we diagnosed 2 GDD patients secondary to citrin deficiency. Figure 2 illustrated the
MS-MS findings suggestive of citrin deficiency in a male toddler (C0013) at his age of 1 year and 4 months, who presented with persistent GDD due to prolonged hepatosplenomegaly and recurrent ascites that progressed into lethal hepatic encephalopathy at his age of 1 year and 10 months. GDD was transient in another 7-month-old infant (C0016) with neonatal intrahepatic cholestasis caused by citrin deficiency (NICCD, OMIM \#605814), who demonstrated catch-up development after recovery of dyslipidemia and abnormal liver function indices. As shown in Figure 3, mutation analysis of the causative gene SLC25A13 clearly confirmed their diagnosis of 851 del 4 homozygotes.

3.4. Congenital Dysmorphic Disorders. In this NDDs cohort, 14 kinds and 22 cases of congenital dysmorphic disorders 

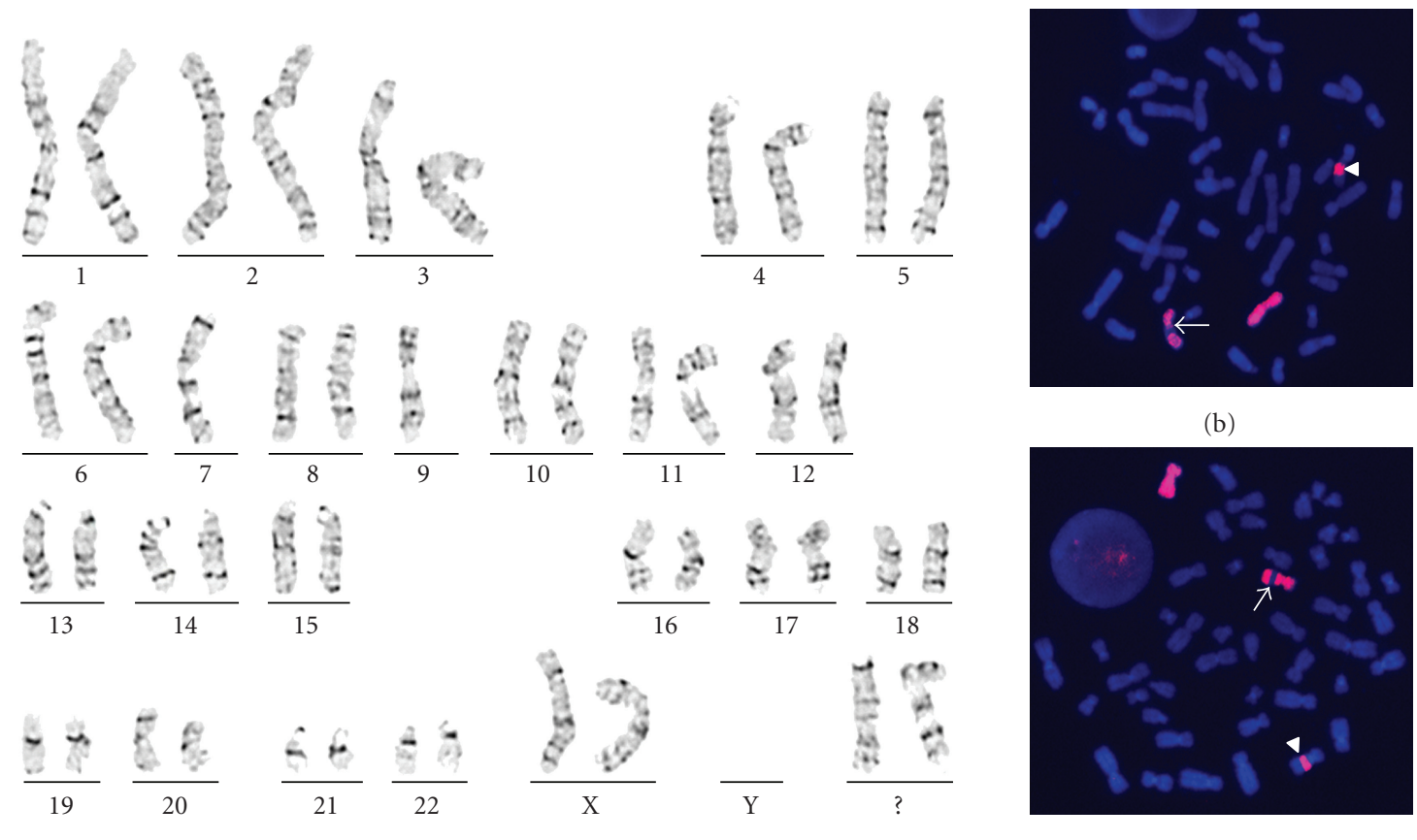

(a)
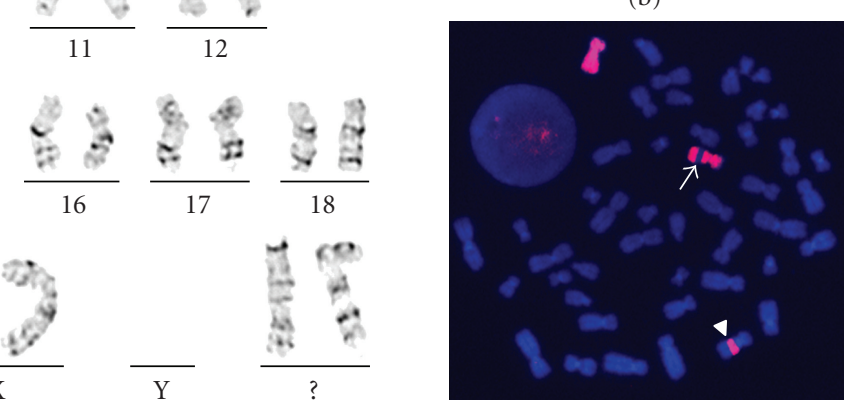

(c)

FIgURE 5: Chromosome abberation in a 6-year-old female with mental retardation (MR). High-resolution GTG-banding in Figure 5(a) revealed the derivative chromosomes 7 and 9 (question mark), and their detailed identities were further illustrated by the results of FISH analysis. Figure 5(b) showed four red signals in a metaphase, by means of utilization of whole chromosome 7 painting probe (WCP 7, red). The normal chromosome 7 had one intact red signal, but the derivative chromosome 7 (arrow) had two dispersed red signals, and a fragment of chromosome 7 (arrowhead) was inserted into a chromosome 9, forming a derivative chromosome 9. Similarly, FISH analysis with WCP 9 (red) in Figure 5(c) showed the normal chromosome 9 with intact red signal, the derivative chromosome 9 (arrow) with two dispersed red signals, and the derivative chromosome 7 with a inserted fragment of chromosome 9 (arrowhead). Finally, the chromosome karyotype in this patient was identified as 46, XX, ins (7;9) (p13; q32q22) inv(7) (p11.2 q11.23), ins (9;7) (q22; q22q32), ish ins(7;9) (WCP7+, WCP9+), ins $(9 ; 7)(\mathrm{WCP} 7+$,WCP9+).

were diagnosed. Most of them were, as shown in Table 5, malformations of cortical development (MCD) such as Miller-Dieker syndrome, Muscle-Eye-Brain disease, and isolated lissencephaly sequence. Figure 4 demonstrated representative MRI findings in the different MCD types. Other CNS malformations like Dandy-Walker syndrome and spinocerebellar ataxia, and some rare syndromes including Silver-Russell syndrome, Noonan syndrome, Poland-Moebius syndrome, and Crisponi syndrome, were also found in our clinical practice. To our knowledge, the patient with Crisponi syndrome reported here is the first case in China.

3.5. Chromosome Karyotypes. By traditional chromosome analysis, karyotype abnormalities were found in 6 patients. Among them, 3 patients were diagnosed as having Down's syndrome (trisomy 21) and 1 Patau's syndrome (trisomy 13), respectively. The remaining 2 were both complex karyotypes, with mos. 47, XX, +der (15) (pter $\rightarrow$ q14::q14 $\rightarrow$ pter $)[11] / 48, \mathrm{XX},+\operatorname{der}(15)($ pter $\rightarrow \mathrm{q} 14:: \mathrm{q} 14 \rightarrow$ pter $) / \times 2$ [12]. ish der(15) (WCP15+, UBE3A++, PML-) in 1 case, and 46, XX, inv ins (7;9) (p13; q32q22) inv(7) (p11.2 q11.23), ins (9;7) (q22; q22q32), ish(7;9) (WCP7+,WCP9+), ins (9;7) (WCP7+,WCP9+) in another, as illustrated in Figure 5. So far as we know, the last karyotype is a novel one that has never been reported in any other references. The patient with this novel abnormal karyotype was a 6-year-old female with mental retardation. History inquiry revealed motor retardation, and examination uncovered dysmorphic facial features including hypertelorism, downward eyeslant, and low-set ears, constituting a clinical phenotype of syndromic NDD.

3.6. Endocrine and Other Genetic Disorders. As shown in Table 3, endocrine and other genetic disorders also played important roles in NDD development in this cohort. Figure 6 clearly demonstrated not only the muscular lesions on electronic microscopy observation, but also the existence of leukodystrophy in MRI which indicated the involvement of central nervous system and thus explained in part the neurodevelopmental retardation in the patient with congenital muscular dystrophy. It is also noteworthy that a hypothyroidism patient in this study was combined with hypophosphatasia with remarkable delay in bone ossification as the radiological feature due to the reduced activity of alkaline phosphatase. To our knowledge, the combined clinical spectra of hypothyroidism and hypophosphatasia in the same patient, once again, have never been reported in other references. 


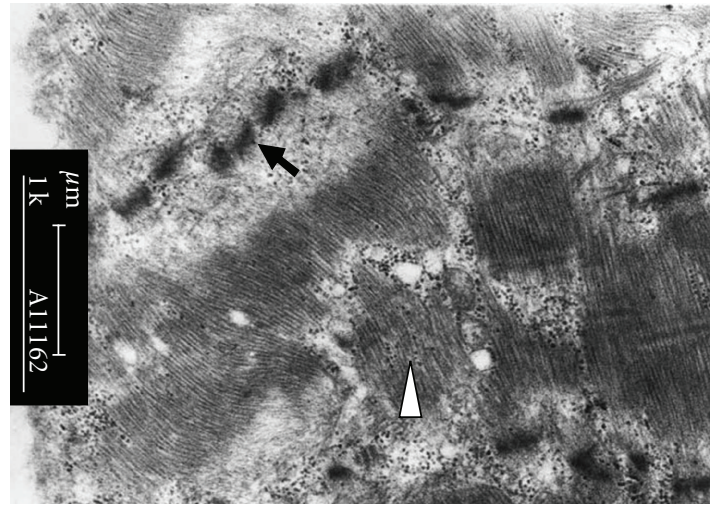

(a)

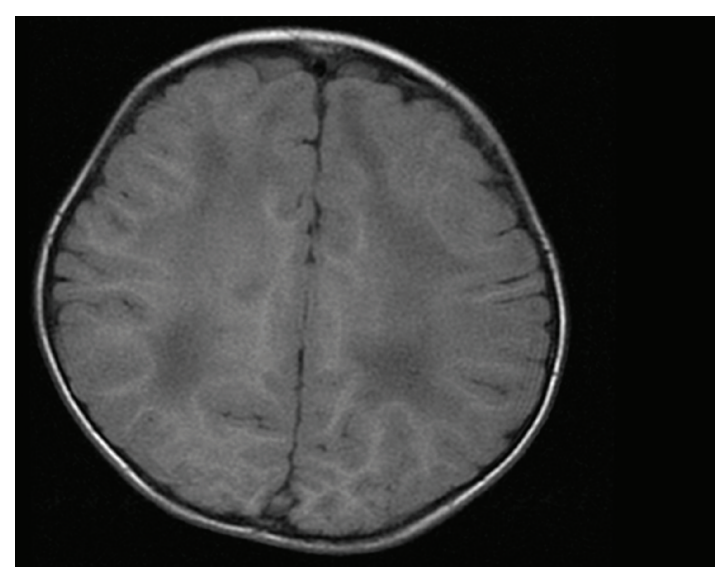

(c)

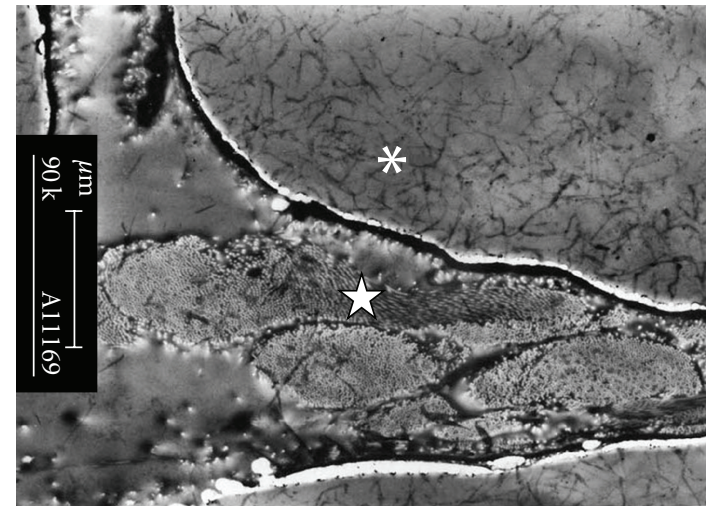

(b)

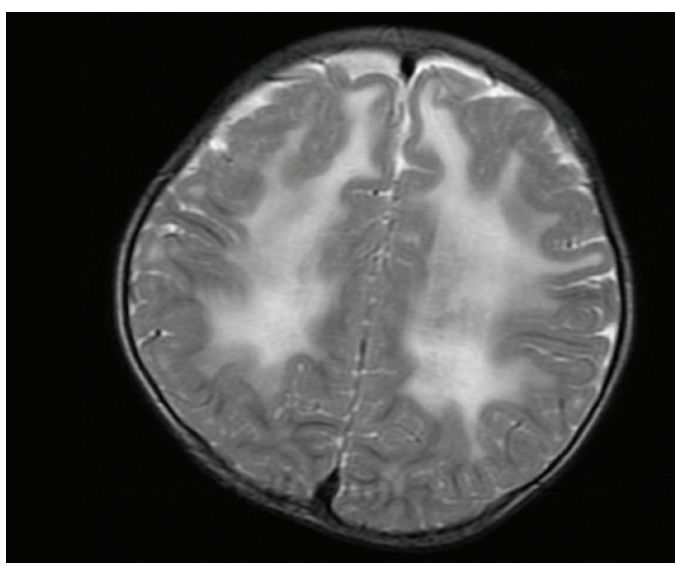

(d)

FIGURE 6: Muscular ultrastructure and brain MRI findings in a patient with congenital muscular dystrophy. In Figure 6(a), the myofibril $\mathrm{Z}$ lines in a muscle cell were ruptured $(\uparrow)$, and the filaments between Z lines were arranged disorderly $(\triangle)$. Figure 6(b) showed the fatty degeneration of myofibrils $(*)$ in a muscle cell with completely vanished sarcolemma, and large quantity of collagenous fibers ( $)$ were observed in the endomysium (Bar $=1 \mu \mathrm{m}$ ). Figures 6(c) and 6(d) were cranial MRI findings revealing the reduced signal intensity in T1WI while increased one in T2WI, respectively, in bilateral frontal and parietal lobes, both indicating leukodystrophy.

\section{Discussion}

The findings in this study provided the latest clinical epidemiology information on the etiology distribution of NDDs in Chinese children. As shown in Table 2, nearly half of the NDD cases could not be attributed to concrete etiologies. This finding indicated the current issue or challenge that we are facing and was consistent with the well-known fact that the etiologies in a substantial percentage of NDDs patients are undiagnosed even after a comprehensive evaluation [13]. On the other hand, concrete etiologies were identified for $51.6 \%$ of the total NDD cases, and the etiology distribution in this cohort demonstrated a rather heterogeneous feature. Autism spectrum disorders (ASDs) have been well recognized as pervasive NDDs entities, and there have been evidences suggesting that some genes or chromosomal abberations are associated with ASDs [14-16]. However, genetic studies have not provided substantial insight into the $90 \%$ of cases of autism whose cause is idiopathic, and the relative genetic contribution to a susceptibility to autism from de novo mutations, rare mutations, and common polymorphisms has been debated extensively [17]. Therefore, autism was categorized into psychobehavioral disorders other than genetic diseases in this paper. This investigation also found 7 NDD cases caused by kernicterus and hypoxemic and ischemic encephalopathy (HIE) which were secondary to 2 curable and even preventable diseases, hyperbilirubinemia and birth asphyxia, respectively. The existence of these 7 cases further suggested the brain vulnerability to exogenous injuries in children, especially in fetuses and neonates. We also found cerebral palsy and epilepsy as NDD etiologies in this NDD cohort, with several cases of refractory epilepsy. However, it is noteworthy that, considering the brain vulnerability once again and the possible effects of antiepileptic drugs (AEDs) on neurodevelopment $[18,19]$, every child with epilepsy must be evaluated on an individual basis as to the risk and benefit of any particular AED used and the role of ongoing treatment [20].

In this eight-year clinical study, various laboratory technologies were conducted in the fields of clinical biochemistry, neuroimaging, biochemical genetics, cytogenetics, molecular 
TABle 5: Congenital dysmorphic disorders in the patients with genetic diseases in Table 3.

\begin{tabular}{|c|c|c|}
\hline Disorders & Cases & Main clinical/imaging features \\
\hline Cortical dysplasia & 1 & $\begin{array}{l}\text { Motor developmental retardation and microcephaly. Severe cortex dysplasia } \\
\text { in parietal lobe and frontal, temporal and occipital lobes, respectively, on } \\
\text { cranial MRI scanning. }\end{array}$ \\
\hline Tuberous sclerosis & 1 & $\begin{array}{l}\text { Intelligence and motor retardation, seizures, cutaneous hypomelanotic } \\
\text { macules, fondus ocili depigmentation, and subependymal nodules and } \\
\text { calcified lesions in the cortex of parietal and temporal lobes on cranial CT } \\
\text { scanning }\end{array}$ \\
\hline Miller-Dieker syndrome & 2 & $\begin{array}{l}\text { Intelligence and motor retardation, microcephaly, prominent occiput, narrow } \\
\text { forehead, small nose and chin. Seizure in } 1 \text { case and hypertonia in another } \\
\text { one. Agyria/pachygyria cortical malformations on MRI. }\end{array}$ \\
\hline Muscle-Eye-Brain disease & 2 & $\begin{array}{l}\text { Sibling sisters with global developmental delay. Abnormal pupils and vitreous } \\
\text { bodies in both cases on ophthalmologic examination. Convulsions in } 1 \text { case } \\
\text { and small right eyeball in another. Both have increased creatine kinase levels } \\
\text { and cobblestone cortical malformations on MRI. }\end{array}$ \\
\hline Isolated lissencephaly sequence & 1 & $\begin{array}{l}\text { Intelligence and motor retardation, and bilateral thickened and irregular } \\
\text { cortex on MRI }\end{array}$ \\
\hline Lissencephaly with cerebellar hypoplasia & 1 & $\begin{array}{l}\text { Mental/language retardation, drooling, and bilateral pachygyria } \\
\text { malformation and hypoplasia of cerebellum revealed by MRI. }\end{array}$ \\
\hline Other malformations of cortical development & 6 & $\begin{array}{l}\text { All have intelligence and motor retardation. Including } 2 \text { cases of cobblestone } \\
\text { cortical malformations and } 1 \text { classic lissencephaly revealed by CT/MRI. }\end{array}$ \\
\hline Dandy-Walker syndrome & 1 & $\begin{array}{l}\text { Intelligence and motor retardation with low-set and everted ears, and } \\
\text { hypoplasia and upward rotation of the cerebellar vermis and cystic dilation of } \\
\text { the fourth ventricle on MRI. }\end{array}$ \\
\hline Spinocerebellar ataxia & 1 & $\begin{array}{l}\text { Intelligence and motor retrogression, and severe cerebellar and pons atrophy } \\
\text { together with tiger-eye-like sign at the basal ganglia level and cross-sign at } \\
\text { pons level, respectively, on MRI. }\end{array}$ \\
\hline Neurofibromatosis type I & 1 & $\begin{array}{l}\text { Intelligence and motor retardation, and } 7 \text { cutaneous cafe-au-lait patches with } \\
\text { diameter over } 10 \mathrm{~mm}\end{array}$ \\
\hline Silver-Russell syndrome & 2 & $\begin{array}{l}\text { Both have dysmorphic facial features including triangular face, low-set ears, } \\
\text { flat nasal bridge with extroversion of nostrils and down-curving mouth } \\
\text { corners. Normal head circumference. Asymmetry of the lower extremities. } \\
\text { Postnatal failure to thrive. Intrauterine retardation in } 1 \text { case and linea alba } \\
\text { hernia in another. }\end{array}$ \\
\hline Noonan syndrome & 1 & $\begin{array}{l}\text { Short stature, short neck with redundancy of skin, hypertelorism, downward } \\
\text { eyeslant, low-set ears, cryptorchidism, and poor sucking. Atrial septal defect } \\
\text { and right pulmonic stenosis on ultrasonography. }\end{array}$ \\
\hline Poland-Moebius syndrome & 1 & $\begin{array}{l}\text { Signs of facial palsy, disappeared corneal reflex, and poor sucking and } \\
\text { swallowing. Micrognathia and high-arched palate. Small left hand, ipsilateral } \\
\text { brachydactyly and hypoplasia of the nails and pectoralis major muscle. }\end{array}$ \\
\hline Crisponi syndrome & 1 & $\begin{array}{l}\text { Convulsions in response to stimuli like crying and bathing. Camptodactyly in } \\
\text { hands. Round face, broad nose with anteverted nostrils, and micrognathia. } \\
\text { Major sucking difficulty and frequent apnea. Hyperthermia that led to death. }\end{array}$ \\
\hline
\end{tabular}

genetics, and electronic microscopy as well. Our experiences strongly supported the viewpoint that detailed history inquiry and physical examination are paramount in the evaluation of NDDs, while judicious investigations can be useful adjunct in determining etiology [21]. As the commonest etiology category in this NDD cohort, genetic diseases, as shown in Table 3, also covered a wide profile of different entities, with IEMs on top of the list. The application of two metabolomic technologies, GC-MS and MS-MS, played irreplaceable roles in the identification of various IEM entities in this study (Table 4). Although other skills such as enzymatic activity and gene mutation analysis help us to confirm the diagnosis of IEM in some cases, selective screening for IEMs by means of GC-MS and MS-MS provides the basis or prerequisite for further intensive investigation. The clinical application of these metabolomic tools in mainland of China was initiated from the beginning of this century, however, their indispensable function in chemical diagnosis of IEMs has been affirmed by more and more clinical evidences in our pediatric practice $[6,22,23]$. Actually, mass spectrometry has occupied an increasingly prominent place in clinical chemistry and laboratory diagnostics during the past few decades [24], and nowadays has been recognized as one of the most frequently 
employed methods of detection in the field of metabolome [25]. However, the metabolomic technologies including GCMS and MS-MS analysis in this study sometimes yields nonspecific and nondiagnostic abnormalities. An example is the metabolome feature of NICCD. This entity was prone to be misdiagnosed as tyrosinemia or galactosemia in case just based on the GC-MS and/or MS-MS findings [26, 27].

Citrin deficiency and a rare chromosome karyotype were found in this study as novel causes for GDD and MR, respectively, further expanding the etiology profile of NDDs. Many "new" IEMs have been discovered in the recent years, and some of them have been found to have features of NDDs [28]. Citrin deficiency, first described in Japan and East Asia, is a newly-established IEM now considered as a panethnic disease distributed worldwide $[27,29]$. We have no direct evidence to explain why the 2 citrin-deficient patients in this study presented with syndromic GDDs. However, their GDD manifestations could not be explained with brain injury directly due to deficient citrin, since this aspartate/glutamate carrier (AGC) is predominantly found in liver, kidney, heart, and intestine, but not in brain [29]. Interplay of multiple factors may represent the possible underlying mechanism. For example, secondary galactosemia and tyrosinemia in citrin deficiency, including the 2 cases in this paper, are quite common [26,27], and brain injuries caused by disturbances in the metabolism of galactose and tyrosine have been reported $[12,30]$. The detailed mechanism(s) for the child with novel karyotype to develop MR remains unclear at the current stage. However, the chromosome aberration in this patient produced 4 chromosome breakpoints, changing the genome architecture inevitably, and thus the syndromic MR may result from one or more mechanisms including gene interruption, gene fusion, position effect, unmasking of a recessive allele, presence of a functional polymorphism, and gene transvection effect $[11,31]$, as proved in other disorders of genome architecture such as acute lymphoblastic leukemia [32] and retinitis pigmentosa [33].

\section{Conclusions}

Although the etiologies in nearly half of the patients still remain an unresolved issue in this NDD cohort, genetic diseases including IEMs and congenital dysmorphic diseases constituted the commonest identified etiology category. GCMS and MS-MS, the two key experimental technologies in the field of pediatric metabolomics, proved to be substantially helpful for the exploration of the NDD etiologies in our clinical practice. The findings in this paper provided latest epidemiologic information on the etiology distribution of NDDs in Chinese, and syndromic NDDs caused by citrin deficiency and the novel chromosomal karyotype, respectively, further expanded the etiology spectrum of NDDs.

\section{Acknowledgments}

The authors are grateful to all the patients and their parents for their cooperation, and to those who referred NDD patients to our department. This paper was supported financially in part by Medical Research Fund of Guangdong Province, China (Nos. A2008358 \& A2009366) and Project 81070279 supported by National Natural Science Foundation of China (NSFC), and by Grants-in-Aid for Scientific Research (B: Nos. 16390100 \& 19390096) and for Asia-Africa Scientific Platform Program (AASPP) from the Japan Society for the Promotion of Science.

\section{Conflicts of Interest}

The authors declare that there are no conflicts of interest.

\section{References}

[1] M. Shevell, "Global developmental delay and mental retardation or intellectual disability: conceptualization, evaluation, and etiology," Pediatric Clinics of North America, vol. 55, no. 5, pp. 1071-1084, 2008.

[2] M. Shevell, S. Ashwal, D. Donley et al., "Practice parameter: evaluation of the child with global developmental delay: report of the quality standards subcommittee of the American Academy of Neurology and The Practice Committee of the Child Neurology Society," Neurology, vol. 60, no. 3, pp. 367380, 2003.

[3] J. Chelly, M. Khelfaoui, F. Francis, B. Chérif, and T. Bienvenu, "Genetics and pathophysiology of mental retardation," European Journal of Human Genetics, vol. 14, no. 6, pp. 701-713, 2006.

[4] M. Yeargin-Allsopp, C. C. Murphy, J. F. Cordero, P. Decouflé, and J. G. Hollowell, "Reported biomedical causes and associated medical conditions for mental retardation among 10 year old children, metropolitan Atlanta, 1985 to 1987," Developmental Medicine and Child Neurology, vol. 39, no. 3, pp. 142-149, 1997.

[5] Y. W. Jiang, "Enhance neurogenetic etiologic studies actively and standardize diagnosis of neurodevelopmental disorders," Zhonghua Er Ke Za Zhi, vol. 47, pp. 561-564, 2009 (Chinese).

[6] Y. Z. Song, B. X. Li, H. Hao et al., "Selective screening for inborn errors of metabolism and secondary methylmalonic aciduria in pregnancy at high risk district of neural tube defects: a human metabolome study by GC-MS in China," Clinical Biochemistry, vol. 41, no. 7-8, pp. 616-620, 2008.

[7] L. S. Han, J. Ye, W. J. Qiu, X. L. Gao, Y. Wang, and X. F. $\mathrm{Gu}$, "Selective screening for inborn errors of metabolism on clinical patients using tandem mass spectrometry in China: a four-year report," Journal of Inherited Metabolic Disease, vol. 30, no. 4, pp. 507-514, 2007.

[8] D. H. Cheng, Y. Q. Tan, Y. F. Di, L. Y. Li, and G. X. Lu, "Crypt $\mathrm{Y}$ chromosome fragment resulting from an $\mathrm{X} ; \mathrm{Y}$ translocation in a patient with premature ovarian failure," Fertility and Sterility, vol. 92, no. 2, pp. 828-e3, 2009.

[9] Y. Z. Song, M. Ushikai, K. Kobayashi, and T. Saheki, "Citrin deficiency is an important etiology for cholestatic liver disease in children," Zhonghua Er Ke Za Zhi, vol. 47, no. 8, pp. 624627, 2009 (Chinese).

[10] M. G. Mohaupt, R. H. Karas, E. B. Babiychuk et al., "Association between statin-associated myopathy and skeletal muscle damage," Canadian Medical Association Journal, vol. 181, no. 1-2, pp. E11-E18, 2009.

[11] D. Kumar, "Disorders of the genome architecture," Genomic Medicine, vol. 2, no. 3-4, pp. 69-76, 2008. 
[12] A. M. Bosch, H. D. Bakker, A. H. van Gennip, J. V. van Kempen, R. J. A. Wanders, and F. A. Wijburg, "Clinical features of galactokinase deficiency: a review of the literature," Journal of Inherited Metabolic Disease, vol. 25, no. 8, pp. 629-634, 2002.

[13] J. B. Moeschler, "Genetic evaluation of intellectual disabilities," Seminars in Pediatric Neurology, vol. 15, no. 1, pp. 2-9, 2008.

[14] J. T. Glessner, K. Wang, G. Cai et al., "Autism genome-wide copy number variation reveals ubiquitin and neuronal genes," Nature, vol. 459, no. 7246, pp. 569-572, 2009.

[15] P. Szatmari, A. D. Paterson, L. Zwaigenbaum et al., "Mapping autism risk loci using genetic linkage and chromosomal rearrangements," Nature Genetics, vol. 39, no. 3, pp. 319-328, 2007.

[16] L. A. Weiss, Y. Shen, J. M. Korn et al., "Association between microdeletion and microduplication at 16 p11.2 and autism," The New England Journal of Medicine, vol. 358, no. 7, pp. 667675, 2008.

[17] X. Zhao, A. Leotta, V. Kustanovich et al., "A unified genetic theory for sporadic and inherited autism," Proceedings of the National Academy of Sciences of the United States of America, vol. 104, no. 31, pp. 12831-12836, 2007.

[18] A. P. Aldenkamp, G. Baker, O. G. Mulder et al., "A multicenter, randomized clinical study to evaluate the effect on cognitive function of topiramate compared with valproate as addon therapy to carbamazepine in patients with partial-onset seizures," Epilepsia, vol. 41, no. 9, pp. 1167-1178, 2000.

[19] D. W. Loring and K. J. Meador, "Cognitive side effects of antiepileptic drugs in children," Neurology, vol. 62, no. 6, pp. 872-877, 2004.

[20] J. H. Cross, "Neurodevelopmental effects of anti-epileptic drugs," Epilepsy Research, vol. 88, no. 1, pp. 1-10, 2010.

[21] L. McDonald, A. Rennie, J. Tolmie, P. Galloway, and R. McWilliam, "Investigation of global developmental delay," Archives of Disease in Childhood, vol. 91, no. 8, pp. 701-705, 2006.

[22] L. S. Han, J. Ye, W. J. Qiu et al., "Diagnosis of inborn errors of metabolism using tandem mass spectrometry and gas chromatography mass spectrometry," Zhonghua Yi Xue Za Zhi, vol. 88, no. 30, pp. 2122-2126, 2008 (Chinese).

[23] X. P. Luo, M. T. Wang, H. Wei et al., "Application of gas chromatography-mass spectrometry analysis on urine filter paper in the high-risk screening and diagnosis of inherited metabolic diseases," Zhonghua Er Ke Za Zhi, vol. 41, no. 4, pp. 245-248, 2003 (Chinese).

[24] A. R. Spitzer and D. Chace, "Proteomics- and metabolomicsbased neonatal diagnostics in assessing and managing the critically ill neonate," Clinics in Perinatology, vol. 35, no. 4, pp. 695-716, 2008.

[25] S. G. Villas-Bôas, S. Mas, M. Åkesson, J. Smedsgaard, and J. Nielsen, "Mass spectrometry in metabolome analysis," Mass Spectrometry Reviews, vol. 24, no. 5, pp. 613-646, 2005.

[26] T. Ohura, K. Kobayashi, Y. Tazawa et al., "Clinical pictures of 75 patients with neonatal intrahepatic cholestasis caused by citrin deficiency (NICCD)," Journal of Inherited Metabolic Disease, vol. 30, no. 2, pp. 139-144, 2007.

[27] Y. Z. Song, B. X. Li, F. P. Chen et al., "Neonatal intrahepatic cholestasis caused by citrin deficiency: clinical and laboratory investigation of 13 subjects in mainland of China," Digestive and Liver Disease, vol. 41, no. 9, pp. 683-689, 2009.

[28] M. A. Kayser, "Inherited metabolic diseases in neurodevelopmental and neurobehavioral disorders," Seminars in Pediatric Neurology, vol. 15, no. 3, pp. 127-131, 2008.
[29] T. Saheki, K. Inoue, A. Tushima, K. Mutoh, and K. Kobayashi, "Citrin deficiency and current treatment concepts," Molecular Genetics and Metabolism, vol. 100, pp. S59-S64, 2010.

[30] A. M. Sgaravatti, B. A. Vargas, B. R. Zandoná et al., "Tyrosine promotes oxidative stress in cerebral cortex of young rats," International Journal of Developmental Neuroscience, vol. 26, no. 6, pp. 551-559, 2008.

[31] J. R. Lupski and P. Stankiewicz, "Genomic disorders: molecular mechanisms for rearrangements and conveyed phenotypes," PLoS Genetics, vol. 1, no. 6, article e49, 2005.

[32] C. M. Rubin, J. J. Carrino, M. N. Dickler, D. Leibowitz, S. D. Smith, and C. A. Westbrook, "Heterogeneity of genomic fusion of BCR and ABL in Philadelphia chromosome-positive acute lymphoblastic leukemia," Proceedings of the National Academy of Sciences of the United States of America, vol. 85, no. 8, pp. 2795-2799, 1988.

[33] L. Köhn, S. J. Bowne, L. S. Sullivan et al., "Breakpoint characterization of a novel $\sim 59 \mathrm{~kb}$ genomic deletion on $19 \mathrm{q} 13.42$ in autosomal-dominant retinitis pigmentosa with incomplete penetrance," European Journal of Human Genetics, vol. 17, no. 5, pp. 651-655, 2009. 

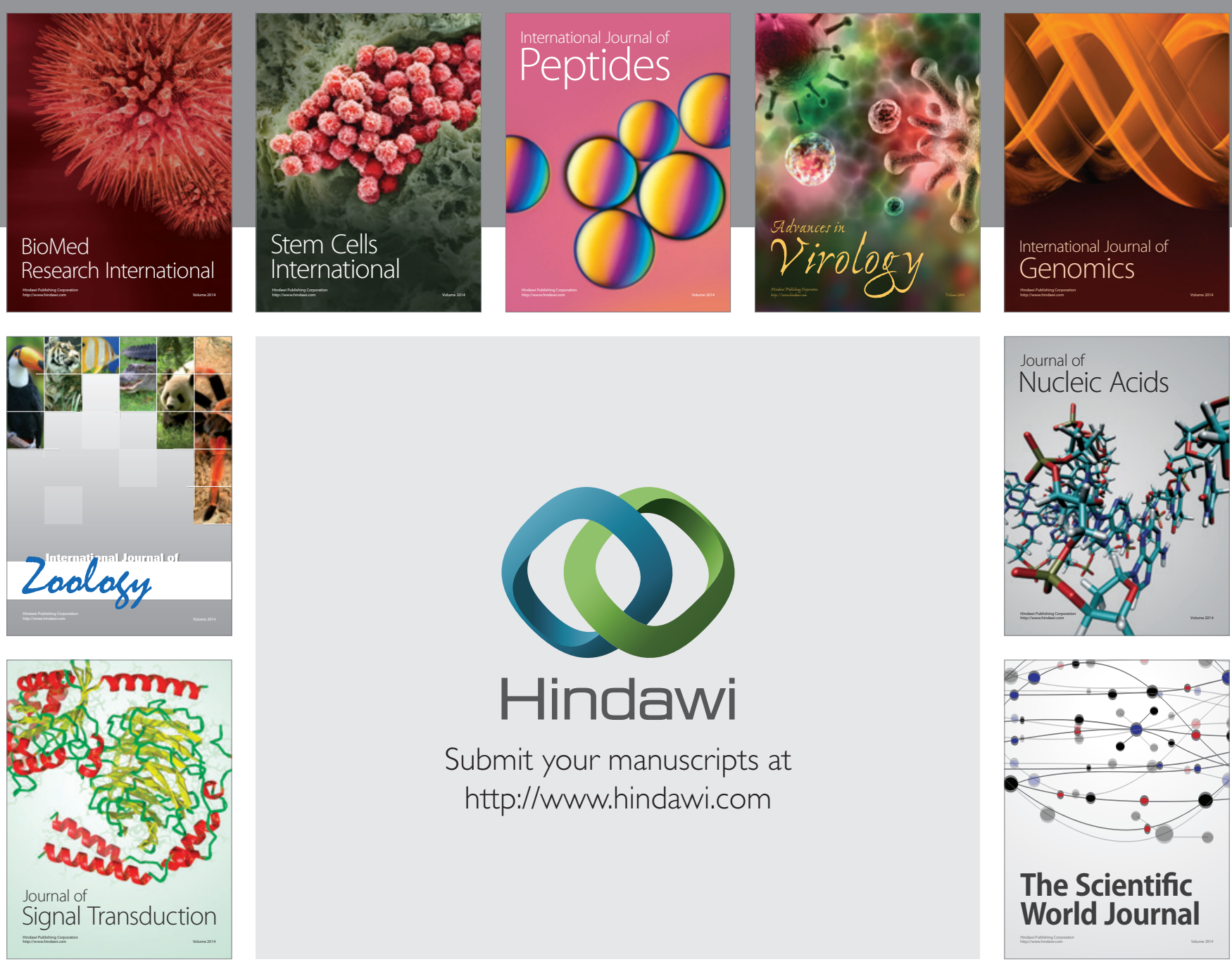

Submit your manuscripts at

http://www.hindawi.com
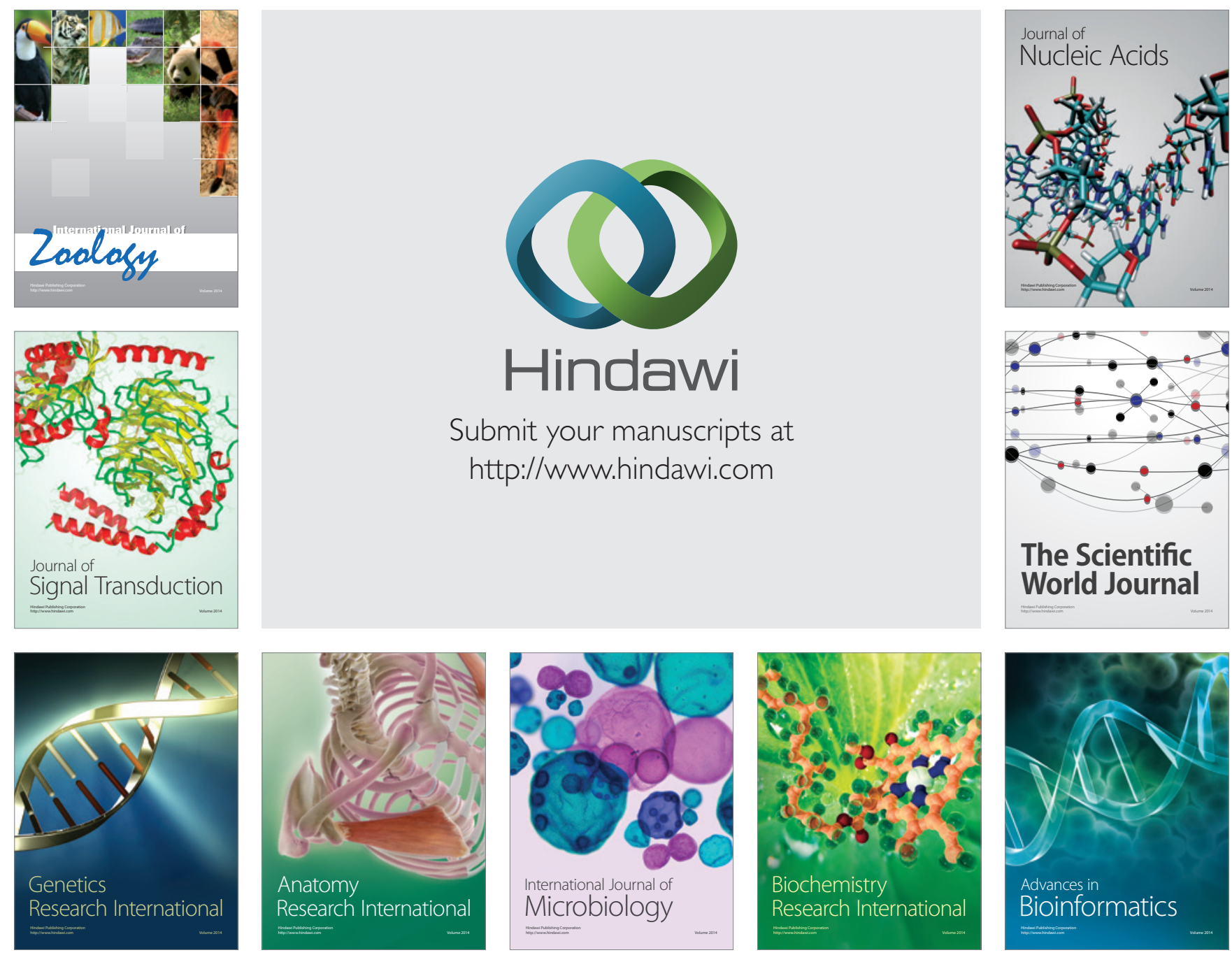

The Scientific World Journal
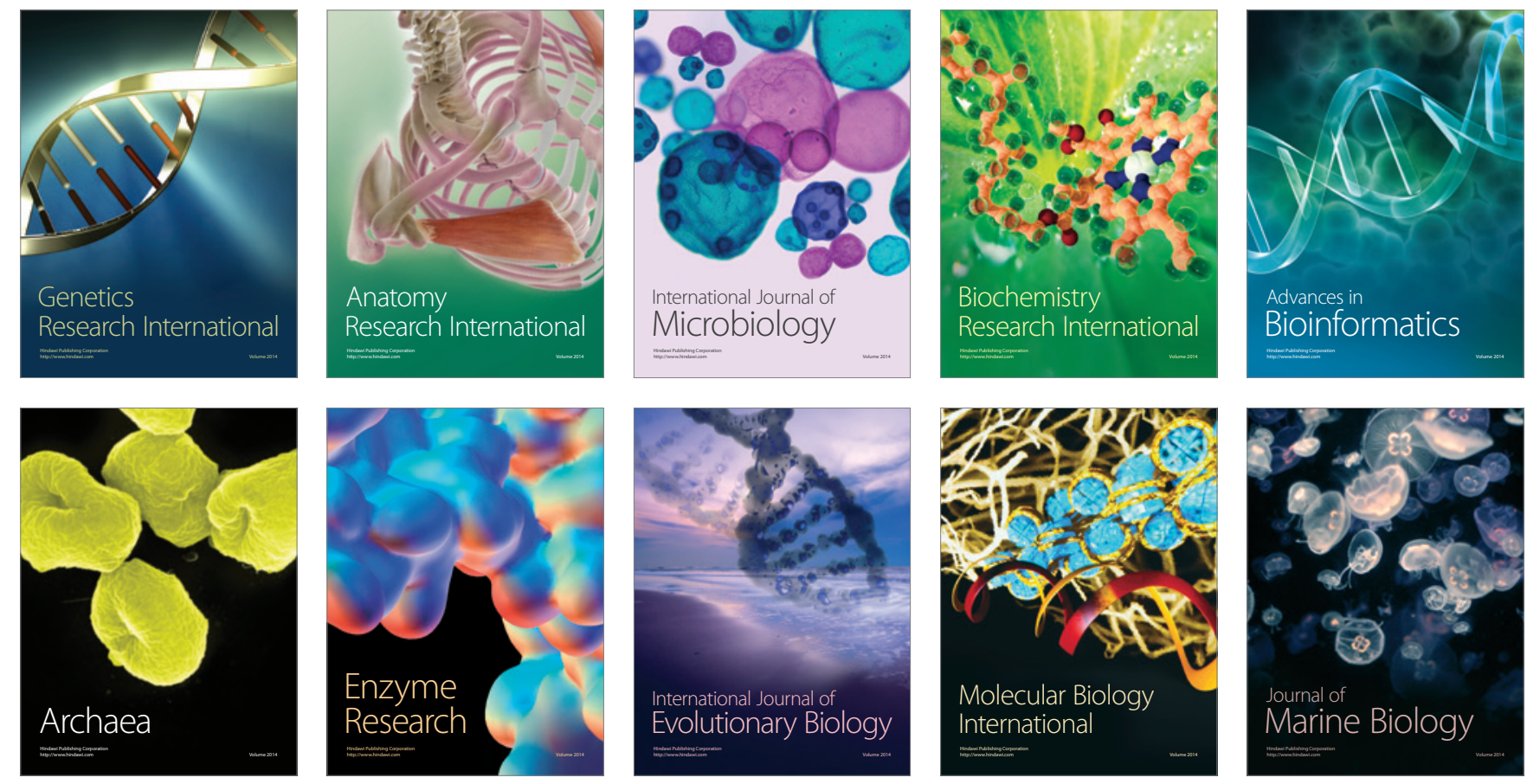